\title{
The Spatio-temporal Epidemiology of Asthma Patient Visits in Relation to Meteorological Parameters and Air Pollution Factors as a Result of Seasonal Change in Songkhla Province
}

\author{
Surichai Bilheem, M.Sc. ${ }^{1}$, Thitiworn Choosong, Ph.D. ${ }^{1,2}$, Hutcha Sriplung, M.D. ${ }^{3}$, \\ Wirat Eungpoonsawat, DP.H. ${ }^{4}$, Chanon Kongkamol, M.D., Ph.D. ${ }^{1,2}$, \\ Thammasin Ingviya, M.D., Ph.D. ${ }^{1,2}$, Jiraporn Soramad, M.Sc. ${ }^{4}$ \\ 'Department of Family and Preventive Medicine, Faculty of Medicine, Prince of Songkla University, Hat Yai, \\ Songkhla 90110, Thailand. \\ ${ }^{2}$ Air Pollution and Health Effect Research Center, Prince of Songkla University, Hat Yai, Songkhla 90110, Thailand. \\ ${ }^{3}$ Epidemiology Unit, Faculty of Medicine, Prince of Songkla University, Hat Yai, Songkhla 90110, Thailand. \\ ${ }^{4}$ National Health Security Office, District 12, Hat Yai, Songkhla 90110, Thailand.
}

Received 16 October 2020 • Revised 3 March 2021 • Accepted 12 March 2021 • Published online 24 June 2021

\begin{abstract}
:
Objective: To investigate the demographic characteristics, seasonal variations, effects associated with air pollution, and geographic morbidity of asthma in Songkhla.

Material and Methods: This research conducted a time series analysis of secondary data from 1 January, 2013 to 31 December, 2017. The distributed lag non-linear model was employed to analyze associations between air pollutants and daily asthma outpatient visits, and the Bayesian hierarchical modelling was used to map asthma morbidity spatiotemporally. Results: A total of 250,127 asthma diagnoses corresponding to 36,761 patients were found in the medical records. Most asthma outpatients were female (61.1\%); males (1-5 years) constituted the majority of individuals during the first peak, while females (40-50 years) predominated the second peak. The trend analysis revealed a seasonal variation in the number of asthma outpatient visits; the highest rates were during the June-December period. The regression coefficient analysis revealed carbon monoxide (CO), nitrogen dioxide $\left(\mathrm{NO}_{2}\right)$, relative humidity, and visibility to have the most
\end{abstract}

Contact: Assoc. Prof. Thitiworn Choosong, Ph.D.

Department of Family and Preventive Medicine, Faculty of Medicine, Prince of Songkla University, Hat Yai, Songkhla 90110, Thailand.

Air Pollution and Health Effect Research Center, Prince of Songkla University,

Hat Yai, Songkhla 90110, Thailand.

E-mail: thicho@hotmail.com, cthitiwo@medicine.psu.ac.th

() 2021 JHSMR. Hosting by Prince of Songkla University. All rights reserved.

This is an open access article under the CC BY-NC-ND license

(http://www.jhsmr.org/index.php/jhsmr/about/editorialPolicies\#openAccessPolicy).
J Health Sci Med Res 2022;40(1):67-84 doi: 10.31584/jhsmr.2021822 www.jhsmr.org 
significant positive effect on asthma, while the cos (wind direction) had the highest negative effect/Impact. Significant associations were found between outpatient gender and age and $\mathrm{CO}, \mathrm{NO}_{2}$, sulfur dioxide, ozone, and particulate matter less than 10 micron. The Hat Yai and Central districts of Songkhla province were identified as morbidity hotspots.

Conclusion: The number of asthma-related outpatient visits increased during the rainy season. Asthma affected primarily young boys and middle-aged women in this province, and they constitute the most sensitive group to air pollutants such as $\mathrm{CO}$ and $\mathrm{NO}_{2}$ and meteorological conditions like relative humidity and visibility. The highest morbidity rates were found in urbanized habitats.

Keywords: air pollution, asthma, outpatient visit, seasonal, spatio-temporal

\section{Introduction}

According to the World Health Organization (WHO), about 300 million of the world's population have asthma and, among them, 250,000 die each year. ${ }^{1}$ In Thailand, a population-based asthma survey in adults showed that $6.7 \%$ of asthmatic patients used inhaled corticosteroids and $14.8 \%$ were admitted to hospital. ${ }^{2}$ A survey by Strategy and Planning Division (SPD) found that, in 2017, the highest number of asthma patient visits was in the South-265.72 per 100,000 population. According to the 43 Songkhla Provincial Public Health databases, the number of patient visits with an asthma diagnosis increased significantly from 27,666 in 2014 to 37,866 in 2015 and 52,283 in 2016 . $^{3}$

Disease situations have distinctive characteristics in each area and do not occur by accident or randomly. The physical and biological characteristics of a particular area are the determinants of geographic epidemiological disease occurrences. ${ }^{4}$ The secondary data that are recorded systematically can be utilized to describe the association between populations, societies, and environmental factors such as climate change and air pollutants, which are major issues of public health. ${ }^{5}$ In determining the disease situation in an area, the geographic information must be considered together with environmental and population contributing factors.
Songkhla province is located in the east of the Lower South of Thailand, and it is the third largest province by area of the Southern Region. It is characterized by an increasing population, rapid economic growth, and a developed manufacturing sector, which consists of 286 factories that include power plants, and rubber and food-processing factories. ${ }^{6}$ They are considered to cause adverse environmental and health consequences that impact the province's population.

There is proof that air pollution episodes lead to increased respiratory irritation, asthma and hospitalization. ${ }^{7}$ Traffic and industrial pollution is related to the release of carbon monoxide (CO) and nitrogen dioxide ( $\mathrm{NO}_{2}$ ) gases, which are associated with asthma outpatient visits. Higher levels of ozone $\left(\mathrm{O}_{3}\right)$, sulfur dioxide $\left(\mathrm{SO}_{2}\right)$, and particulate matter less than 10 micron $\left(\mathrm{PM}_{10}\right)$ have reportedly been associated with increased asthma visits and hospital admissions. In addition to the effects of pollution on asthma, another important element affecting asthma are meteorological factors. ${ }^{8}$

Our extensive literature review indicated that no comprehensive investigation on asthma, utilizing complex spatial modelling for the analysis of geographical data, has ever been carried out in this region of Thailand. The daily exposure level, measured via the geostatistical method, and the corresponding asthma visits were linked to estimate 
the impact of air pollutants on asthma visits. The results were compared among different age- and genderdependent asthma risk groups. The objective of these analyses was to assess the effects of meteorological factors and air pollution on asthma. This is important since it can help identify the causes of asthma outbreaks and, thus, inform the creation and implementation of more targeted and effective health interventions and practices as well as the design of public health policies aimed at specifically preventing the exposure of patients with asthma to risky environmental factors.

We analyzed the data from the reported number of asthma patient visits to healthcare facilities in Songkhla province from 2013 to 2017 in order to: 1) describe the demographic characteristics and seasonal variations of asthma outpatient visits; 2) investigate possible associations between air pollution $\left(\mathrm{CO}, \mathrm{SO}_{2}, \mathrm{NO}_{2}, \mathrm{O}_{3}, \mathrm{PM}_{10}\right)$ and asthma outpatient visits; and 3) consider the geographical location and time together as factors associated with the morbidity rate of asthma at the sub-district level.

\section{Material and Methods}

This study was conducted in Songkhla province (South of Thailand), with an area of approximately 7,393.9 $\mathrm{km}^{2}$ (see additional file 1), a UTM zone of $47 \mathrm{~N}$, and coordinates from $7^{\circ} 12^{\prime} 22^{\prime \prime} \mathrm{N}$ to $100^{\circ} 35^{\prime} 48^{\prime \prime} \mathrm{E}$. It is divided into 16 districts, which are further subdivided into 127 sub-districts and 987 villages. Seasons are divided according to weather and seasonal changes in Southern Thailand-they are the summer season (mid-February to mid-May) and the rainy season (mid-May to mid-February).

Computerized claims data from the Bureau of National Health Security Office (NHSO) Region 12 Songkhla were used in this study. No personally identifiable information was utilized in accordance with Thailand's Personal Data Protection Law. The service claims for outpatient visits ascertaining asthma as the principal diagnosis were reviewed (International Classification of Diseases, Ninth Revision, Clinical Modification Code 493.x). ${ }^{9}$ Daily counts of hospital outpatient visits, Emergency Department Visits, and clinic visits for asthma derived from medical insurance files for the service dates from January 2013 to December 2017, totaling 1,825 days, were included in the analysis. Each event related to a person on a given day was counted as one visit and was limited to Songkhla province only. The analysis covered all genders, ages, and the status of permanent residence using sub-district codes according to the Department of Provincial Administration. We omitted potentially miscoded data concerning outpatient visits to departments such as ophthalmology, dermatology, dentistry, etc., which were considered unlikely to have asthma as a diagnosis. The Humen Research Ethic Committee board of Prince of Songkla University, Songkhla, Thailand approved the study (EC. 61-037-9-2).

The air pollution and meteorological data were simultaneously collected from January 2013 to December 2017 from two PCD stations located in Songkhla province, five PCD stations located in another province nearby, and The Thailand Meteorological Data Sharing Service (see Additional File 1). The real-time hourly monitoring of air pollutant concentration involving $\mathrm{CO}, \mathrm{NO}_{2}, \mathrm{SO}_{2}, \mathrm{O}_{3}, \mathrm{PM}_{10}$ was performed. The meteorological data comprised daily average temperature $(T)$, rainfall $(R F)$, relative humidity $(\mathrm{RH})$, wind speed (WS), wind direction (WD), atmospheric pressure $(P)$, dew point $(D)$, and visibility $(V)$. We detected biased values using the mean \pm 3 standard deviation range for the purpose of making the determination whether they should be included because such data could affect the analysis results. When air pollutant data for a given day were incomplete, the missing values were calculated via the single imputation technique. The mathematical convention of 0 degrees and 360 degrees indicating the same wind direction was used. Moreover, we calculated the mean of the cosines and sines of each angle in order to determine 
the mean of the series of angles in the interval $0^{\circ}-360^{\circ}$ and find the angle by calculating the inverse tangent.

This study utilized the basic geographic unit of an administrative "sub-district" (127 sub-districts in total) to make assumptions about the patients' location and exposure to air pollution. Each asthma patient visit was matched with the sub-district's daily meteorological data mean in order to assess the effects of the 24-hour average pollutant concentration for that date.

To construct the interpolations of air pollutant measurements and meteorological data of each sub-district, the Ordinary Kriging Technique ${ }^{10}$ was used, considering the data from each monitoring station by date from January 2013 to December 2017. To examine the best fit of the data, we used six kinds of semivariogram, i.e., the separable model, least squares fit, product sum model, manual fit, metric model, and sum-metric model. A Distributed Lag Non-linear Model (DLNM) analysis was performed within generalized additive models (GAMs); the log-link function and the cubic smoothing spline method were used to fit the model assuming that the error structures followed the Poisson distribution. ${ }^{10}$ The final model we specified proved to be the best-fitting one according to the stepwise determination of Akaike's information criterion with a restricted maximum likelihood (REML) (the models are described in the Additional File 2). To consider the air pollution and its lag effect on asthma, the accumulative lag effects were examined with a lag of 15 days for each air pollutant concentration among different population groups. The health impact of each air pollutant was reported as the rate of increase in outpatient visits corresponding to a $10.0 \%$ increase in local air pollution levels. All results are presented as either relative risk (RR) or increased risk (RR-1 * 100\%) with the associating 95\% confidence interval $(95 \% \mathrm{Cl})$. The data management and all statistical analyses were conducted using the R software (version 3.6.1). In addition, the "gstat” package was used for the Kriging approach, the "dlnm” package was employed to fit the distributed lag non-linear model, and the Mixed GAM Computation Vehicle, the "MGCV" package, was applied to construct the analytic model. Moreover, univariate and multivariable analyses were conducted. To assess the inter-relations between air pollutants and meteorological factors on asthma outpatient visits, we employed Spearman's correlation coefficients and the Poisson regression model using the generalized linear model (GLM) function. In the analysis, the daily counts of outpatient visits were paired with the daily meteorological data as well as the 24-hour average pollutant concentration for a total of 1,825 days.

The count of medical care visits from the NHSO databases was used in our study to assess asthma morbidity. We spatiotemporally mapped morbidity trends in Songkhla province, all of its 127 sub-districts, for 5 calendar years-2013, 2014, 2015, 2016, and 2017-based on the Bayesian model with an Integrated Nested Laplace Approximation (INLA). The geographic distribution of asthma incidence during one year is shown on each map. The smallest unit for the INLA computation was sub-district. The observations for each sub-district were allocated to a distinct geographical central point, which was defined as the median coordinates of each sub-district's borders. The outputs were $\mathrm{x}$ and $\mathrm{y}$ for the Bayesian estimation model and estimated morbidity pixels $(x, y)$ for the Cartesian coordinate system. The outputs with themed colors were plotted on a dense grid in the domain and overlaid with the boundaries of the province and its districts. The progressive color change corresponded to the relative change in the estimated morbidity rate [low (indigo) - high (red)]. We used the "INLA" package in R software to perform the spatiotemporal maps. 


\section{Results}

\section{Baseline characteristics}

Tables 1 and 2 summarize the statistical characteristics of asthma outpatient visits to healthcare facilities, as well as the air pollutants and meteorological factors in Songkhla province from 2013 to 2017 . The overall results showed that 250,127 medical records corresponding to 36,761 patients had a diagnosis of asthma, with a morbidity rate of 448.9 per 10,000 population. Most outpatient visits involved females, 19,761 patients (53.8\%). The number of asthma diagnosis visits was 152,892 (61.1\%), 529.97 per 10,000 population. When considering the age distribution, adults (20-64 years) had the highest number of total asthma visits $(49.3 \%)$, and a morbidity rate of 362.41 per 10,000 population. During the studied period, the daily average concentrations of $\mathrm{PM}_{10}, \mathrm{NO}_{2}, \mathrm{SO}_{2}, \mathrm{O}_{3}$, and $\mathrm{CO}$ were 31.28 $\mu \mathrm{g} / \mathrm{m}^{3}, 6.71$ parts per billion (ppb), $1.97 \mathrm{ppb}, 22.75 \mathrm{ppb}$, and 0.47 parts per million (ppm), respectively, which were lower than the Thai national primary ambient air quality standards for air pollutants. The highest daily average $\mathrm{PM}_{10}$ concentration was $182.09 \mu \mathrm{g} / \mathrm{m}^{3}$, exceeding Thailand's ambient air quality standard $\left(120 \mu \mathrm{g} / \mathrm{m}^{3}\right.$ for $\left.\mathrm{PM}_{10}\right)$. As for the meteorological conditions during the studied period, the daily average temperature and relative humidity were 27.84 ${ }^{\circ} \mathrm{C}$ and $80.6 \%$, respectively, reflecting the tropical climate of southern Thailand. Figure 1 shows that the use of health services by asthma outpatients increased over time, illustrating a similarity in distribution patterns for both genders. Females consistently had a higher number of visits than males. The data indicated that June and December were the two peak months in the years 2015, 2016, and 2017. Meanwhile, the distribution pattern for the years 2013 and 2014 was indistinctive due to missing data on children visits. Figure 2 shows the significant gender differences across the lifespan of asthmatics. The age of asthmatics can be separated into 3 age-related groups: children (0-19 years), adults (20-64 years), and elderly (>64 years) (Additional File 3).

Table 1 Characteristics and distributions of asthma outpatient visits in Songkhla province, stratified by gender and age group, from January 1, 2013 to December 31, 2017 (a total of 1,825 days)

\begin{tabular}{|c|c|c|c|c|c|c|c|c|c|}
\hline \multirow{2}{*}{ Variable } & \multirow{2}{*}{$\begin{array}{l}\text { Number of } \\
\text { cases (\%) }\end{array}$} & \multirow{2}{*}{ Mean+S.D. } & \multirow{2}{*}{$\begin{array}{l}\text { Number of } \\
\text { outpatient } \\
\text { visits (\%) }\end{array}$} & \multicolumn{5}{|c|}{ Percentile of outpatient visits } & \multirow{2}{*}{$\begin{array}{l}\text { Morbidity } \\
\text { rate per } 10^{\wedge} \\
\text { population }\end{array}$} \\
\hline & & & & Min & $25^{\text {th }}$ & $50^{\text {th }}$ & $75^{\text {th }}$ & $\operatorname{Max}$ & \\
\hline Total & 36,761 & $6.79 \pm 10.09$ & 250,127 & 1 & 1 & 2 & 8 & 279 & 448.86 \\
\hline \multicolumn{10}{|l|}{ Gender } \\
\hline Male & $17,000(46.2)$ & $5.72 \pm 8.50$ & $97,235(38.9)$ & 1 & 1 & 2 & 7 & 174 & 361.79 \\
\hline Female & $19,761(53.8)$ & $7.72 \pm 11.20$ & $152,892(61.1)$ & 1 & 1 & 3 & 10 & 279 & 529.97 \\
\hline \multicolumn{10}{|c|}{ Age groups (years) } \\
\hline $0-19$ & $15,314(41.7)$ & $4.88 \pm 6.69$ & $74,752(29.9)$ & 1 & 1 & 2 & 6 & 117 & 455.03 \\
\hline $20-64$ & $15,467(42.1)$ & $7.83 \pm 11.67$ & $123,421(49.3)$ & 1 & 1 & 3 & 10 & 279 & 362.41 \\
\hline$\geq 65$ & $5,980(16.3)$ & $7.70 \pm 10.34$ & $51,954(20.8)$ & 1 & 1 & 3 & 11 & 111 & 991.24 \\
\hline
\end{tabular}


Table 2 Descriptive statistics for data concerning air pollutant density and meteorological factors from January 1, 2013 to December 31, 2017 (a total of 1,825 days)

\begin{tabular}{|c|c|c|c|c|c|c|c|}
\hline \multirow{2}{*}{ Item } & \multirow{2}{*}{ Mean \pm S.D. } & \multirow{2}{*}{$\begin{array}{l}\text { Geometric } \\
\text { mean }\end{array}$} & \multicolumn{5}{|c|}{ Percentiles } \\
\hline & & & Min & $25^{\text {th }}$ & Median & $75^{\text {th }}$ & Max \\
\hline \multicolumn{8}{|l|}{ Air pollutant } \\
\hline $\mathrm{PM}_{10}\left(\mu \mathrm{g} / \mathrm{m}^{3}\right)$ & $31.28 \pm 10.76$ & 29.94 & 13.73 & 24.66 & 28.96 & 35.69 & 182.09 \\
\hline $\mathrm{NO}_{2}(\mathrm{ppb})$ & $6.71 \pm 2.13$ & 6.41 & 1.87 & 5.30 & 6.34 & 7.75 & 20.70 \\
\hline $\mathrm{SO}_{2}^{2}(\mathrm{ppb})$ & $1.97 \pm 0.86$ & 1.78 & 0.11 & 1.38 & 1.85 & 2.43 & 7.28 \\
\hline $\mathrm{O}_{3}^{2}(\mathrm{ppb})$ & $22.75 \pm 8.86$ & 21.21 & 7.68 & 16.28 & 20.88 & 27.51 & 74.42 \\
\hline $\mathrm{CO}(\mathrm{ppm})$ & $0.47 \pm 0.11$ & 0.46 & 0.24 & 0.40 & 0.46 & 0.52 & 1.19 \\
\hline \multicolumn{8}{|l|}{ Meteorological factors } \\
\hline Temperature $\left({ }^{\circ} \mathrm{C}\right)$ & $27.84 \pm 1.10$ & 27.81 & 23.89 & 27.14 & 27.87 & 28.64 & 31.14 \\
\hline Total rainfall $(\mathrm{mm})$ & $5.88 \pm 11.42$ & 0.00 & 0.00 & 0.08 & 1.90 & 7.24 & 161.44 \\
\hline Relative humidity (\%) & $80.55 \pm 5.06$ & 80.40 & 64.02 & 76.67 & 80.34 & 84.04 & 97.00 \\
\hline Pressure (hPa) & $1,008.88 \pm 1.85$ & $1,008.87$ & $1,003.83$ & $1,007.59$ & $1,008.75$ & $1,010.04$ & $1,015.00$ \\
\hline Dew point $\left({ }^{\circ} \mathrm{C}\right)$ & $23.72 \pm 0.90$ & 23.70 & 18.14 & 23.36 & 23.90 & 24.33 & 25.40 \\
\hline Wind speed (knots) & $13.12 \pm 3.28$ & 12.87 & 7.00 & 11.29 & 12.86 & 14.43 & 108.43 \\
\hline Wind direction (degrees) & $155.42 \pm 77.91$ & 134.49 & 35.71 & 81.43 & 137.14 & 238.57 & 300.00 \\
\hline Visibility (km) & $9.25 \pm 0.87$ & 9.19 & 1.14 & 9.00 & 9.43 & 9.71 & 10.57 \\
\hline
\end{tabular}

$\mathrm{PM}_{10}=$ particulate matter less than 10 micron, $\mu \mathrm{g} / \mathrm{m}^{3}=$ micrograms per cubic meter, $\mathrm{ppb}=$ parts per billion, $\mathrm{NO}_{2}=$ nitrogen dioxide, $\mathrm{SO}_{2}=$ sulfur dioxide, $\mathrm{O}_{3}=$ ozone, $\mathrm{CO}=$ carbon monoxide, ppm=parts per million, hPa=hectopascal

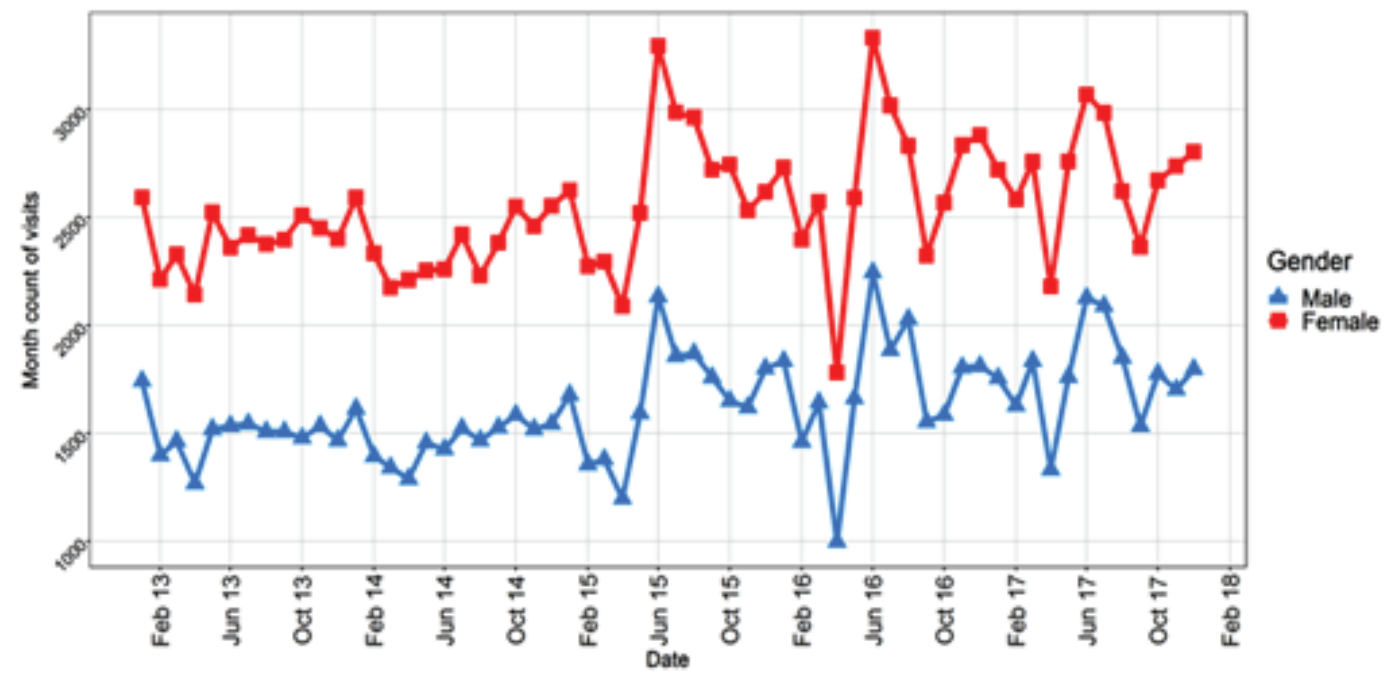

Figure 1 Gender-specific monthly asthma outpatient visits 


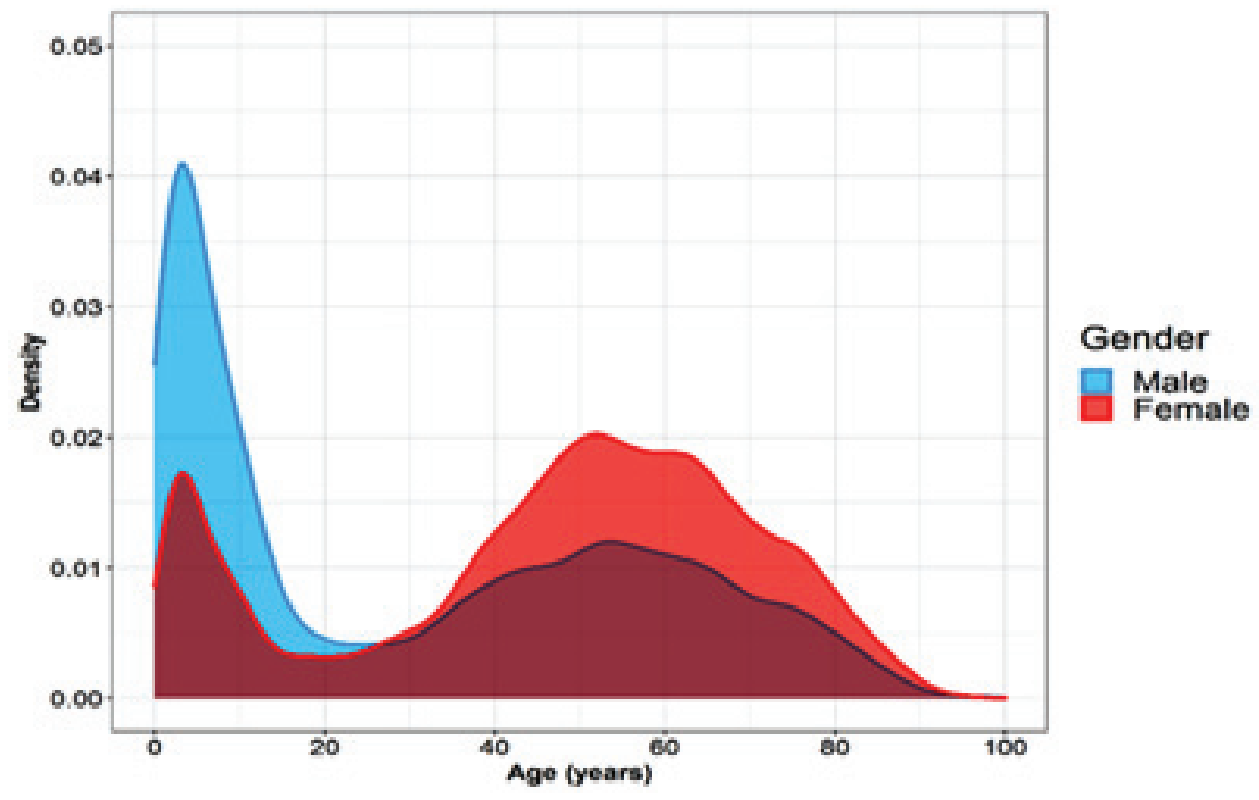

Figure 2 Distribution of asthma outpatient visits stratified by gender and age showing that the highest frequencies involved young boys and middle-aged women

Associations between air pollution, meteorological factors, and outpatient visits

Figure 3 shows that the highest positive corre-lation was between rainfall and relative humidity $(r=0.66, p$-value $<0.001$ ), whereas the highest negative correlation was between temperature and relative humidity $(r=-0.48, p-$ value $<$ 0.001). Weather conditions, e.g., rainfall, relative humidity, atmospheric pressure, dew point, wind speed, and ambient visibility, had negative correlations with $\mathrm{PM}_{10}, \mathrm{NO}_{2}, \mathrm{SO}_{2}, \mathrm{O}_{3}$, and $\mathrm{CO}$. We found positive correlations among $\mathrm{CO}, \mathrm{NO}_{2}$, relative humidity, and dew point and asthma outpatient visits for all ages. Atmospheric pressure showed a negative correlation with asthma visits. As shown in Table 3, the multiple regression analysis revealed $\mathrm{CO}$ having the most significant positive regression weights on all-age asthma outpatient visits, with a regression coefficient value of 0.550 $(p-v a l u e<0.000)$. As for the cos wind direction, it showed as having the highest negative regression weight on asthma visits, with a regression coefficient value of -3.311 ( $p$-value $<$ 0.000).

\section{Health effect}

In this section, we discuss the air pollution's effects on asthma outpatient visits in terms of gender and age group. We used DLNM combined with GAM to determine the lag-response relationship between air pollutants and the RR for asthma outpatient visits adjusted for correlated meteorological variables as shown in Figure 4. It represents the different patterns of the effects of a $10.0 \%$ increase in pollutant concentration on asthma outpatient visits. The spatial distribution, estimated via the Kriging method, indicates the average pollutant concentration in each sub-district where the starting values were $\mathrm{PM}_{10}=35.59 \mu \mathrm{g} / \mathrm{m}^{3}, \mathrm{NO}_{2}=7.09$ $\mathrm{ppb}, \mathrm{SO}_{2}=2.61 \mathrm{ppb}, \mathrm{O}_{3}=26.02 \mathrm{ppb}$, and $\mathrm{CO}=0.50 \mathrm{ppm}$. In terms of gender, a significant association was detected for $\mathrm{PM}_{10}$ on a 4-day lag for the female group; it showed the 


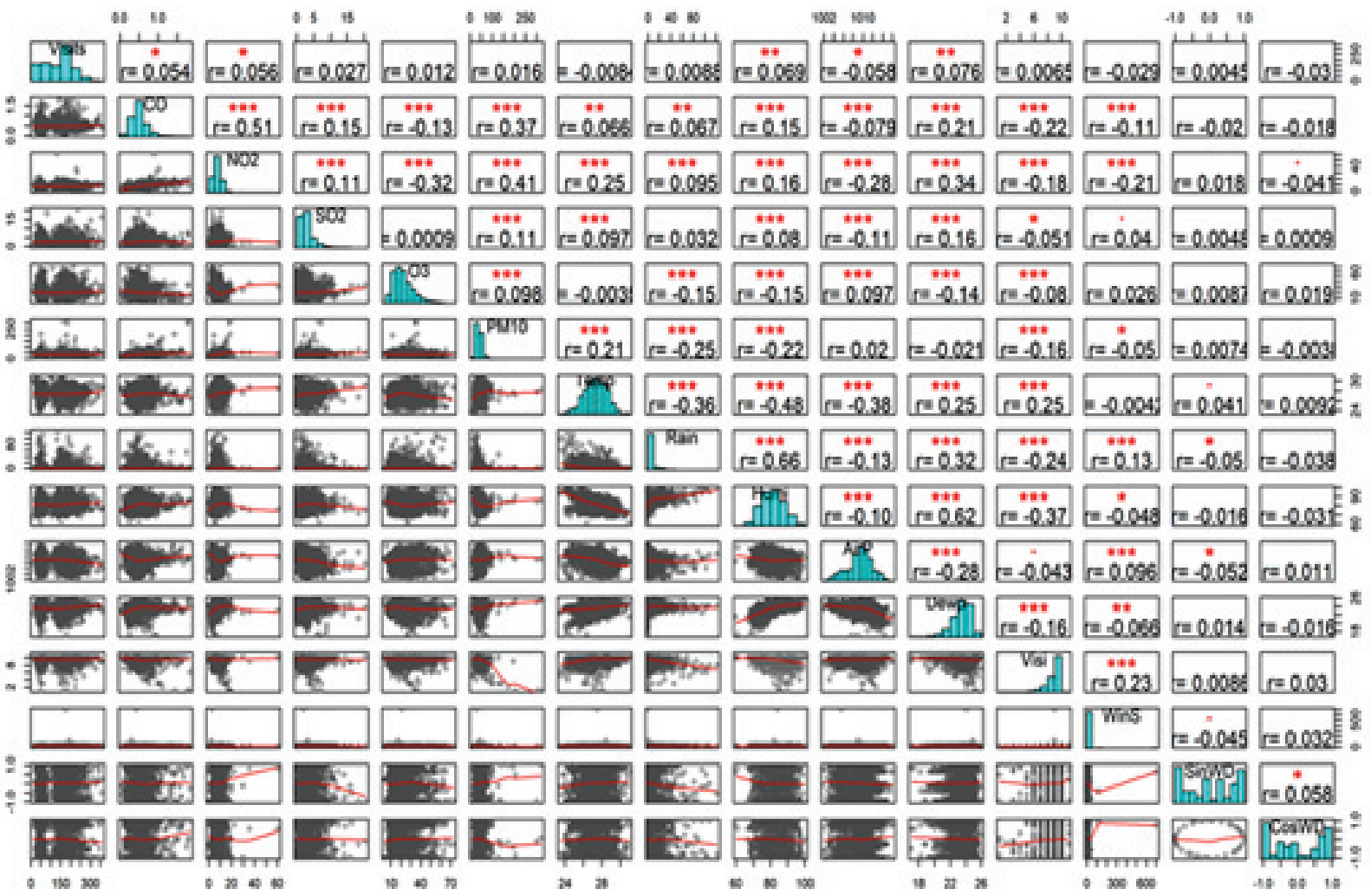

Visits, all-age asthma outpatient visits, $\mathrm{CO}=$ carbon monoxide, $\mathrm{NO}_{2}=$ nitrogen dioxide, $\mathrm{SO}_{2}=$ sulfur dioxide, $\mathrm{O}_{3}=\mathrm{ozone}, \mathrm{PM}_{10}=$ particulate matter less than 10 micron, Temp=temperature, Rain=rainfall, Humi=relative humidity, AirP=atmospheric pressure, Dewp=dew point, Visi=visibility, WinS, wind speed, SinWD=sin (wind direction), CosWD=cos (wind direction).

Figure 3 Spearman's Rank Correlation Matrix between asthma outpatient visits and climate variables from January 1 , 2013 to December 31, 2017 (a total of 1,825 days)

highest increase $(25.6 \%)$ in asthma outpatient visits (RR $=1.256,95 \% \mathrm{Cl}=1.143-1.379$ ). In terms of $\mathrm{O}_{3}$, significant associations were found in the male group with a 0-day lag; a $9.2 \%$ increase in asthma outpatient visits was found ( $R R=1.092,95 \% \mathrm{Cl}=1.058-1.126)$. The results also showed that $\mathrm{SO}_{2}$ and $\mathrm{NO}_{2}$ displayed significant associations with outpatient visits for both males and females at different lag days. However, no significant associations between $\mathrm{CO}$ and asthma visits were observed (Figure 4).
Regarding age, for patients under 19 years old, significant associations between asthma outpatient visits and $\mathrm{NO}_{2}$ were detected; the highest impacts was observed at a 7-day lag, which increased to $13.5 \%(\mathrm{RR}=1.135,95 \% \mathrm{Cl}=$ 1.085-1.187). Meanwhile, $\mathrm{SO}_{2}$ was associated with a $15.8 \%$ increase at a lag of 12 days $(\mathrm{R} R=1.158,95 \% \mathrm{Cl}=1.115-$ 1.201), $\mathrm{O}_{3}$ had a $9.5 \%$ increase at a 0 -day lag $(R R=1.095$, $95 \% \mathrm{Cl}=1.067-1.122)$, and $\mathrm{CO}$ showed a $2.6 \%$ increase at a 12-day lag $(\mathrm{RR}=1.026,95 \% \mathrm{Cl}=1.009-1.043)$. For 
Table 3 Impact of meteorological parameters and air pollutants on asthma outpatient visits in Songkhla province assessed by the Poisson Regression Model using a generalized linear model function (data from January 1, 2013 to December 31, 2017 [a total of 1,825 days])

\begin{tabular}{|c|c|c|c|c|c|}
\hline \multirow{2}{*}{$\begin{array}{l}\text { Parameter } \\
\text { (Constant) }\end{array}$} & \multirow{2}{*}{$\begin{array}{l}\text { Regression } \\
\text { coefficient }\end{array}$} & \multirow{2}{*}{$\begin{array}{l}\text { Std. error } \\
1.432\end{array}$} & \multirow{2}{*}{$\begin{array}{c}\text { z-value } \\
11.542\end{array}$} & \multicolumn{2}{|c|}{ Statistical significance } \\
\hline & & & & 0.000 & $\star \star \star *$ \\
\hline Temperature & 0.017 & 0.009 & 1.874 & 0.061 & \\
\hline Rainfall & -0.002 & 0.000 & -8.168 & 0.000 & $* * *$ \\
\hline Relative humidity & 0.018 & 0.002 & 8.154 & 0.000 & *** \\
\hline Wind speed & 0.005 & 0.001 & 9.963 & 0.000 & $* \star *$ \\
\hline Sin (wind direction) & -0.020 & 0.003 & -6.824 & 0.000 & $* * \star$ \\
\hline Cos (wind direction) & -3.311 & 0.003 & -11.931 & 0.000 & *** \\
\hline Pressure & -0.014 & 0.001 & -10.274 & 0.000 & $\star \star \star *$ \\
\hline Dew point & -0.047 & 0.010 & -4.787 & 0.000 & *** \\
\hline Visibility & 0.076 & 0.005 & 16.416 & 0.000 & $\star \star \star *$ \\
\hline $\mathrm{CO}$ & 0.550 & 0.022 & 25.160 & 0.000 & *** \\
\hline $\mathrm{NO}_{2}$ & 0.032 & 0.001 & 30.671 & 0.000 & $\star \star \star *$ \\
\hline $\mathrm{SO}_{2}^{2}$ & 0.002 & 0.002 & 0.702 & 0.483 & \\
\hline $\mathrm{O}_{3}^{2}$ & 0.004 & 0.000 & 15.575 & 0.000 & *** \\
\hline $\mathrm{PM}_{10}^{3}$ & 0.000 & 0.000 & 0.297 & 0.767 & \\
\hline
\end{tabular}

${ }^{* * *}$ p-value $<0.001$

$\mathrm{Sin}$ (wind direction)=wind from the south, $\mathrm{Cos}$ (wind direction)=wind from the west, $\mathrm{CO}=$ carbon monoxide, $\mathrm{NO}_{2}=$ nitrogen dioxide, $\mathrm{SO}_{2}=\mathrm{Sulfur}$ dioxide, $\mathrm{O}_{3}=$ ozone, $\mathrm{PM}_{10}=$ particulate matter less than 10 micron

patients aged from 20 to 64 years, significant associations with $\mathrm{PM}_{10}$ were detected; the highest impact, an increase of $44.5 \%$, was observed at a lag of 4 days $(R R=1.445,95 \%$ $\mathrm{Cl}=1.281-1.629$ ). In addition, $\mathrm{NO}_{2}$ was associated with a $6.9 \%$ increase at a 0 -day lag $(\mathrm{RR}=1.069,95 \% \mathrm{Cl}=1.018-$ 1.122), $\mathrm{SO}_{2}$ with a $12.7 \%$ increase at a 10 -day lag, $(\mathrm{RR}=$ $1.127,95 \% \mathrm{Cl}=1.069-1.189)$, and $\mathrm{O}_{3}$ with a $5.1 \%$ increase at a 0-day lag $(R R=1.051,95 \% \mathrm{Cl}=1.022-1.082)$. For patients older than 65, significant associations were detected with $\mathrm{PM}_{10}, \mathrm{NO}_{2}$, and $\mathrm{O}_{3}$; they showed an increase of $30.2 \%$ at a lag of 6 days $(R R=1.302,95 \% \mathrm{Cl}=1.133-1.498)$, of $11.0 \%$ at a lag of 15 days $(R R=1.109,95 \% \mathrm{Cl}=1.045-1.178)$, and of $3.6 \%$ at a lag of 0 days $(R R=1.036,95 \% \mathrm{Cl}=1.000-1.072)$, respectively (Figure 4).

\section{Morbidity rate}

The spatiotemporal maps of the smoothed morbidity rate in Songkhla province were divided into calendar years from 2013 to 2017, as shown in Figure 5. The spatial influence on asthma outpatient visits revealed that the highest morbidity was located around Songkhla Lake (220-740 per 10,000 population). In the same area, the tendency of morbidity rate of asthma increased temporally in a timeevolving fashion. The biggest temporal rates cover these sub-district areas: the northeast of Hat Yai, the west of Mueang, the middle of Bang Klam, the middle of Khuan Niang, the northeast of Rattaphum, the northeast of Ranot, and the smallest one was observed in the southwest of Sadao. The geographical distribution plots of the subdistrict-level morbidity rates for initializing the starting value of smoothing parameters are shown in Additional File 4. 

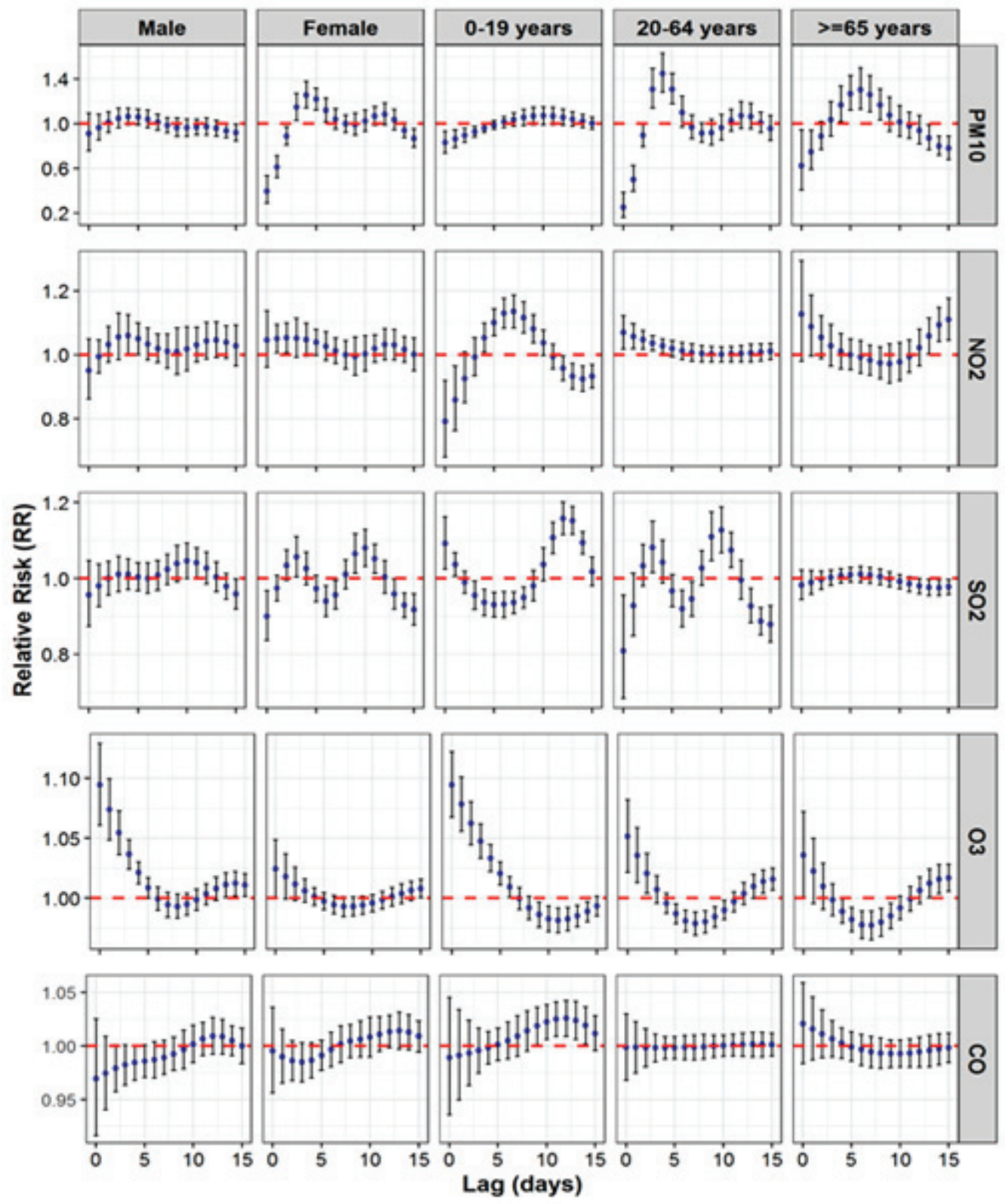

Figure 4 Lag-response relationship between air pollutants and the relative risk for asthma outpatient visits for different population groups 

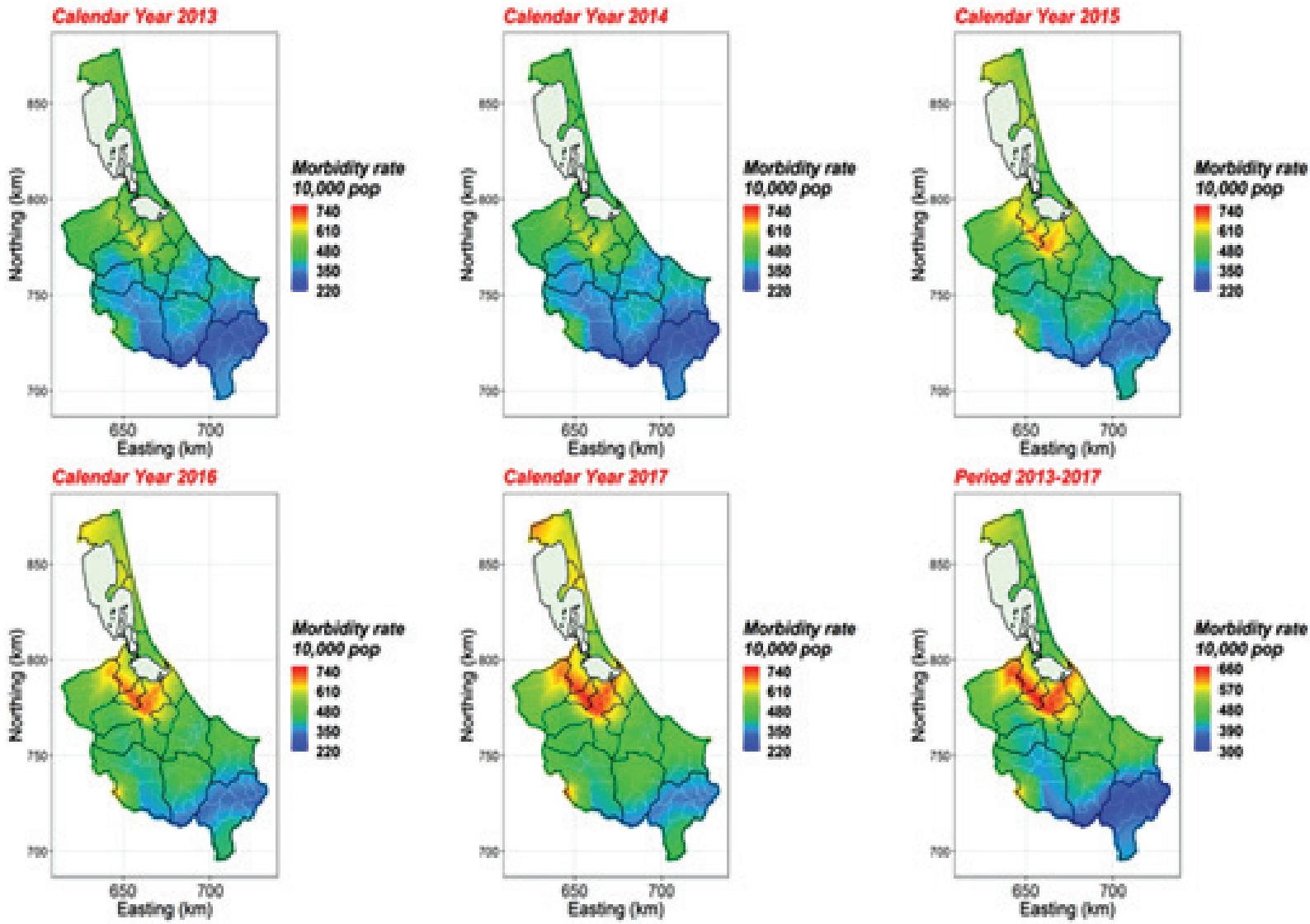

Figure 5 Spatial and temporal mapping of morbidity rate on asthma outpatient visits in Songkhla province for 5 calendar years using the Cartesian coordinate system

\section{Discussion}

The number of asthma patient visits was affected by seasonal changes; they tended to decrease in February (summer season) and increase in June through December (rainy season). This increase in visits was caused by the weather conditions during the rainy season, which complies with the hypothesis that most asthma attacks occur during the rainy season. ${ }^{11}$ However, pollutant inhalation, smoking, and social and economic status, which are also main causes of a higher asthma incidence during rainy season, should be of concern. ${ }^{12}$

A previous study on asthma and its management confirmed that $62.0 \%$ of patients were female ${ }^{13}$, a finding which is consistent with that of our study $(61.0 \%$ were female asthma patients). In this study, we suggested that asthma patients be divided into three age groups (children aged 0-19 years, adults aged 20-64 years, and the elderly aged over 64 years), which is in line with a previous study that identified boys and middle-aged women a high-risk groups. $^{14}$

It is noted that the causes of asthma are multifactorial, and many studies have found significant associations between asthma morbidity and air pollutant variables. ${ }^{15}$ The main results yielded by this study suggest that pollutants such as $\mathrm{CO}, \mathrm{NO}_{2}, \mathrm{SO}_{2}, \mathrm{O}_{3}$, and $\mathrm{PM}_{10}$ impact asthma patients significantly, but they impact varies with 
gender, age, and length of exposure (at lags of 0-15 days). Regarding $\mathrm{CO}$, its adverse effects correlated to the treatment of asthma patients of all age groups and resulted in a significant acute exacerbation after a 12-day exposure; ${ }^{16}$ it was also associated with a distinct asthma treatment among boy and girl groups, and there was evidence suggesting that it may result in acute exacerbation of clinical status among boys after 2-4 days of exposure. ${ }^{17}$ This finding is in compliance with those of other studies ${ }^{18}$, which have reported that $\mathrm{CO}$ is statistically significantly associated with the highest impact level on the number of both outpatients and inpatients. This and other recent studies indicate that the pulmonary functions of asthma patients worsen when they are exposed to a lower concentration of $\mathrm{CO}$, below the $\mathrm{WHO}$ air quality guidelines.

As it regards $\mathrm{NO}_{2}$, the findings of this research concur with those of an earlier study conducted among children aged 0-14 years. ${ }^{19}$ According to it, the estimated effect of $\mathrm{NO}_{2}$ was related to patients of all age groups, and the highest occurrence of symptoms was after a 3-day exposure. The inhalation of $\mathrm{NO}_{2}$ results in lung irritation and is accompanied by bronchial stenosis symptoms, particularly in those having asthma. ${ }^{20}$

Concerning exposure to $\mathrm{SO}_{2}$, even though its daily average concentration is quite low, bronchial tube contractions and a decrease in pulmonary efficiency have been reported to be caused by it $^{21}$, especially after a 2-day exposure. $^{22}$

In terms of $\mathrm{O}_{3}$, as ozone level increases, so does its impact on asthma children aged under 18 years, with symptoms appearing after a 2-day exposure. ${ }^{23}$ However, not all studies have found such a positive link between the two; ${ }^{24}$ some have reported no significant association between $\mathrm{O}_{3}$ and asthma hospital admissions in all age groups, including children under 14 years of age. Additionally, both the trend and change in monthly average of $\mathrm{O}_{3}$ in this study were higher at the end of December and the beginning of January, which is similar to the findings of a previous study. ${ }^{25}$

As for $\mathrm{PM}_{10}$, a $10.0 \%$ increase showed a significant association with hospital/outpatient visits among females aged 20-64 years and those older than 64 years. It has been reported that an increase by $10 \mu \mathrm{g} / \mathrm{m}^{3}$ in $\mathrm{PM}_{10}$ concentration impacts asthma symptoms 6-7 days after exposure in adult patients. ${ }^{26}$ Even if, this study found a lower average $\mathrm{PM}_{10}$ level than the $\mathrm{WHO}$ guidelines, which did not exceed $50 \mu \mathrm{g} / \mathrm{m}^{3}$ per 24-hour, the movement characteristics of the time series indicated that a peak $\mathrm{PM}_{10}$ was 70 times higher than the standard values.

The number of asthma visits and morbidity rate in the South are among the highest compared to the other four regions in Thailand, and the factors causing severe asthma symptoms and associated with the most adverse impacts are the effects of climate change. ${ }^{13}$ This study's results indicate that relative humidity and visibility were distinctive variables with an obvious and significant detrimental impact on asthma patients' health.

Relative humidity in the atmosphere enhances stimulants that have a clinical significance for asthma patients, resulting in higher incidents of asthma during the rainy season; however, this weather condition is pervasive throughout the whole year due to Thailand's tropical climate. ${ }^{27}$

Regarding visibility, this study revealed on average visibility of $9.25 \mathrm{~km}$. (the lowest was $1.14 \mathrm{~km}$, and the highest was $10.57 \mathrm{~km}$ ), signifying that, in general, the atmospheric mass concentrations in Songkhla are at neutral levels compared to the Visibility Preference Studies to the Health-related Air Quality Index, which was determined a normal visibility of 9.66 kilometers. ${ }^{28}$ Additionally, studies from other countries have indicated that a lower visibility is related to poor air quality, which is associated with higher adverse effects on respiratory diseases. ${ }^{29}$ Therefore, if relative humidity increases and visibility decreases, not only does visibility impacts asthma patients negatively, but it effect is compounded by the high level of humidity. ${ }^{30}$ 
In terms of wind direction, this study showed the highest negative correlation between it and asthma outpatients. The two yearly monsoons that affect Songkhla province differ to some extent. The southwest monsoon typically begins in mid-May and ends in mid-October, whereas the northeast monsoon generally begins in mid-October and ends in mid-February. ${ }^{31}$ These and other differences related to geography and climate may, depending on the case, increase or decrease the transport distance of allergens, leading to certain areas being less affected than others. ${ }^{32}$ Concerning atmospheric pressure, previous studies have demonstrated both positive and negative correlations between it and asthma. ${ }^{33,34}$ Studies conducted in Japan and London have revealed a negative correlation between asthma and atmospheric pressure, which corresponds to our results. ${ }^{34,35}$ The role of climatic factors (e.g., atmospheric pressure, temperature, and humidity) in triggering asthma attacks has been proven; they have been connected with both low $^{35}$ and high atmospheric pressure. ${ }^{36}$ Thus, we deem that either a peak or a low in asthma patient visits is plausible following a fall in air temperature and air pressure, and an increase in relative humidity. The dew point temperature is one of the indicators of the amount of moisture in the air. This study's univariate analysis revealed positive inter-relations, while the multivariate analysis showed negative inter-relations between dew point and asthma visits. In addition, the growth of microorganisms on building materials due to moisture influences moisture's association with asthma and results on the moisture content of such materials being of primary interest for asthma. ${ }^{37}$ One factor considered is water vapor condensation, which may occur from air being cooled below its dew point, or the exchange of air between outdoors and indoors, leading to water vapor condensation. ${ }^{37}$

The risk rates for disease occurrence are related to geospatial epidemiology during the entire period of time investigated. We found that the highest number of asthma patients was from Hat Yai and Mueang districts of Songkhla province, which comprise urbanized sub-districts. These findings are consistent with those of an earlier study that found higher respiratory and asthma incidences in urban areas compared to rural ones. ${ }^{38}$

Some of the air quality measurement stations were not located in the data collection sites; therefore, there might have been some biases related to the measurement of individual exposure, which could have affected the results. Even though $\mathrm{PM}_{2.5}$ particles are associated with stronger health effects than $\mathrm{PM}_{10}$ in terms of reducing lung function and leading to more asthma attacks, we used $\mathrm{PM}_{10}$ instead of $\mathrm{PM}_{2.5}$ data because of their sufficiency and reliability. Furthermore, environmental variables such as wind direction and speed may have impacted the air pollutant distributions. ${ }^{31,32}$ Meanwhile, the actual exposure time is hard to be evaluated, and its classification might not be correct due to the time lapse between exposure to air pollutants and hospital admission. ${ }^{39}$ In addition, since the data on children's visits were missing for the 2013-2014 period, and because the asthma patient database of Songkhla province was updated and improved in 2015 and the fact that the ICD-10 disease coding does not specify the asthma type, "J45.9 Asthma, unspecified" was used for more than $92.0 \%$ of cases. In addition, the data did not indicate which patients were truly sick or on continuous medication; therefore, the examined codes for the asthma diagnosis in the medical records may have lacked reliability. ${ }^{40}$

\section{Conclusion}

The number of outpatient visits due to asthma increased during the rainy season, affecting primarily young boys and middle-aged women, who are the most sensitive groups to air pollution, especially to $\mathrm{CO}$ and $\mathrm{NO}_{2}$, as well as to meteorological factors, particularly to visibility and relative humidity. The highest morbidity rates were found in urban areas. Our findings support the efforts of the Thai govern- 
ment in reducing the levels of air pollution in urban areas in order to protect the health of the population. Children and/or their guardians should beware high relative humidity, while both children (or their guardians) and adults should pay attention to air pollutant parameters, especially $\mathrm{CO}$.

\section{Funding sources}

This study was supported by the Graduate Scholarship, Faculty of Medicine, Prince of Songkla University (No. 007, 2016) and the intergrated research program fund of Prince of Songkla University (Grant No. MED620183M).

\section{Conflict of interest}

None

\section{References}

1. Bousquet J, Mantzouranis E, Cruz AA, Aït-Khaled N, Baena-Cagnani CE, Bleecker ER, et al. Uniform definition of asthma severity, control, and exacerbations: document presented for the World Health Organization Consultation on Severe Asthma. J Allergy Clin Immunol 2010;126:926-38.

2. Boonsawat W, Charoenphan P, Kiatboonsri S, Wongtim S, Viriyachaiyo V, Pothirat C, et al. Survey of asthma control in Thailand. Respirology 2004;9:373-8.

3. Songkhla Provincial Public Health Office. Public health report system for outpatient information in Songkhla province [homepage on the Internet]. Songkhla: SKHO; 2013 [cited 2019 Nov 5]. Available from: http://www.skho.moph.go.th/ dataservice/

4. Rashidi M, Poursafa P. Geographic health's way to prevention of diseases: a case study on arsenic spatial dispersion and dyspnea in Isfahan Province. J Prev Med 2014;5:1372-8.

5. Cao $Q$, Liang $Y$, Niu $X$. China's air quality and respiratory disease mortality based on the spatial panel model. J Environ Res Public Health 2017;14:1081.

6. Department of Industrial Works. Data of industry [homepage on the Internet]. Songkhla: DIW; 2011 [cited 2019 Oct 3]. Available from: http://www2.diw.go.th/factory/tumbol.asp

7. Kuo HW, Lai JS, Lee MC, Tai RC, Lee MC. Respiratory effects of air pollutants among asthmatics in central Taiwan. Arch Environ Health 2002;57:194-200.
8. Mireku N, Wang Y, Ager J, Reddy RC, Baptist AP. Changes in weather and the effects on pediatric asthma exacerbations. Allergy Asthma Immunol 2009;103:220-4.

9. Centers for Disease Control and Prevention. ICD-9-CM to ICD-10-CM conversion [homepage on the Internet]. Georgia: CDC; 2019 [cited 2019 Sep 30]. Available from: https://www. cdc.gov/asthma/data-analysis-guidance/CD-9-CM-ICD-10CM.htm

10. Xie X, Semanjski I, Gautama S, Tsiligianni E, Deligiannis N, Rajan $\mathrm{RT}$, et al. A review of urban air pollution monitoring and exposure assessment methods. International Journal of Geo-Information 2017;6:389.

11. Valença LM, Restivo PC, Nunes MS. Seasonal variations in emergency room visits for asthma attacks in Gama, Brazil. J Bras Pneumol 2006;32:284-9.

12. Cohen S, Janicki-Deverts D, Turner RB, Marsland AL, Casselbrant ML, Li-Korotky HS, et al. Childhood socioeconomic status, telomere length, and susceptibility to upper respiratory infection. Brain Behav Immun 2013;34:31-8.

13. Boonsawat W, Thompson PJ, Zaeoui U, Samosorn C, Acar G, Faruqi R, Poonnoi P. Survey of asthma management in Thailand - the asthma insight and management study. Asian Pac J Allergy Immunol 2015;33:14-20.

14. Zein JG, Udeh BL, Teague WG, Koroukian SM, Schlitz NK, Bleecker ER, et al. Impact of Age and Sex on Outcomes and Hospital Cost of Acute Asthma in the United States, 2011-2012. PLoS One 2016;11:e0157301.

15. Pan $\mathrm{HH}$, Chen $\mathrm{CT}$, Sun HL, Ku MS, Liao PF, Lu KH, et al. Comparison of the effects of air pollution on outpatient and inpatient visits for asthma: a population-based study in Taiwan. PLoS One 2014;9:e96190.

16. Peel JL, Tolbert PE, Klein M, Metzger KB, Flanders WD, Todd $\mathrm{K}$, et al. Ambient air pollution and respiratory emergency department visits. Epidemiology 2005;16:164-74.

17. Lin M, Chen Y, Burnett RT, Villeneuve PJ, Krewski D. Effect of short-term exposure to gaseous pollution on asthma hospitalisation in children: a bi-directional case-crossover analysis. J Epidemiol Community Health 2003;57:50-5.

18. Pongpiachan S, Paowa T. Hospital out-and-in-patients as functions of trace gaseous species and other meteorological parameters in Chiang-Mai, Thailand. Aerosol Air Quality Research 2014;15:479-93.

19. Galán I, Tobías A, Banegas JR, Aránguez E. Short-term effects 
of air pollution on daily asthma emergency room admissions. Eur Respir J 2003;22:802-8.

20. Deu JS. Nitrogen dioxide: an unimportant cause of health effects?. J European Respiratory Society 1998;139-40.

21. Aekplakorn W, Loomis D, Vichit VN, Shy C, Wongtim S, Vitayanon $P$. Acute effect of sulphur dioxide from a power plant on pulmonary function of children, Thailand. J Epidemiol 2003; 32:854-61.

22. Atkinson RW, Anderson HR, Strachan DP, Bland JM, Bremner SA, Ponce-de LA. Short-term associations between outdoor air pollution and visits to accident and emergency departments in London for respiratory complaints. Eur Respir J 1999;13:257-65.

23. Lee SL, Wong WH, Lau YL. Association between air pollution and asthma admission among children in Hong Kong. Clin Exp Allergy 2006;36:1138-46.

24. Fusco D, Forastiere F, Michelozzi P, Spadea T, Ostro B, Arcà M, et al. Air pollution and hospital admissions for respiratory conditions in Rome, Italy. Eur Respir J 2001;17:1143-50.

25. Zhang BN, Oanh NK. Photochemical smog pollution in the Bangkok Metropolitan Region of Thailand in relation to $\mathrm{O} 3$ precursor concentrations and meteorological conditions. Atmospheric Environment 2002;6:4211-22.

26. Pothirat C, Tosukhowong A, Chaiwong W, Liwsrisakun C, Inchai J. Effects of seasonal smog on asthma and COPD exacerbations requiring emergency visits in Chiang Mai, Thailand. Asian Pac J Allergy Immunol 2016;34:284-9.

27. Linsuwanon P. Molecular epidemiology and evolutionary studies of human rhinovirus and enterovirus 68 in Thailand [Dissertation]. Bangkok, Chulalongkorn University; 2012.

28. Malm WC. What level of perceived visual air quality is acceptable? [monograph on the Internet]. Fort Collins: Cooperative Institute for Research in the Atmosphere Colorado State University; 2013 [cited 2019 Oct 9]. Available from: https:// www.firescience.gov/projects/13-C-01-01/project/13C-01-01_Malm_Acceptable_Levels_Report_3.pdf

29. Yadav AK, Kumar K, Kasim MHA, Singh MP, Parida SK, Sharan M. Visibility and incidence of respiratory diseases during the 1998 haze episode in Brunei Darussalam. Pure Appl Geophys 2003;160:265-77.

30. Sabbah I, Arifhodzic N, Al-Ahmad M, Ali-Enizi A, Al-Haddad A,
Al-Ajmi N. Influence of air quality conditions on asthmatic patient visits in Kuwait. J Allergy Ther 2014;5:2.

31. Cecchi L, Torrigiani Malaspina T, Albertini R, Zanca M, Ridolo E, Usberti I, et al. The contribution of long-distance transport to the presence of Ambrosia pollen in central northern Italy. Aerobiologia 2007;23:145-51.

32. Sirimongkonlertkun N. Assessment of Long-range Transport Contribution on Haze Episode in Northern Thailand, Laos and Myanmar. Earth Environ Sci 2018;51:012017.

33. Priftis KN, Paliatsos AG, Panagiotopoulou-Gartagani $P$, Tapratzi-Potamianou P, Zachariadi-Xypolita A, Nicolaidou P, et al. Association of weather conditions with childhood admissions for wheezy bronchitis or asthma in Athens. Respiration 2006;73:783-90.

34. Sato S, Saito J, Suzuki Y, Uematsu M, Fukuhara A, Togawa R, et al. Association between typhoon and asthma symptoms in Japan. Respir Investig 2016;54:216-9.

35. Celenza A, Fothergill J, Kupek E, Shaw RJ. Thunderstorm associated asthma: a detailed analysis of environmental factors. BMJ 1996;312:604-7.

36. Garty BZ, Kosman E, Ganor E, Berger V, Garty L, Wietzen T, et al. Emergency room visits of asthmatic children, relation to air pollution, weather and airborne allergens. Ann Allergy Asthma Immunol 1998;81:563-70.

37. Institute of Medicine (US) Committee on the Assessment of Asthma and Indoor Air. Clearing the air: asthma and indoor Air exposures [monograph on the Internet]. Washington: National Academies Press; 2000 [cited 2021 Feb 6]. Available from: https://www.ncbi.nlm.nih.gov/books/NBK224480/

38. D'Amato G, Cecchi L, D'Amato M, Liccardi G. Urban air pollution and climate change as environmental risk factors of respiratory allergy: an update. J Investig Allergol Clin Immunol 2010;20:95-102.

39. Lokken RP, Wellenius GA, Coull BA, Burger MR, Schlaug G, Suh $\mathrm{HH}$, et al. Air pollution and risk of stroke: underestimation of effect due to misclassification of time of event onset. Epidemiology 2009;20:137-42.

40. To T, Dell S, Dick PT, Cicutto L, Harris JK, MacLusky IB, et al. Case verification of children with asthma in Ontario. Pediatr Allergy Immunol 2006;17:69-76. 
Additional file 1 Map with study and monitoring sites. Panel A shows air monitoring stations in Songkhla province and Southern Thailand. Panel B shows a map of Songkhla province, Thailand, with the districts numbered

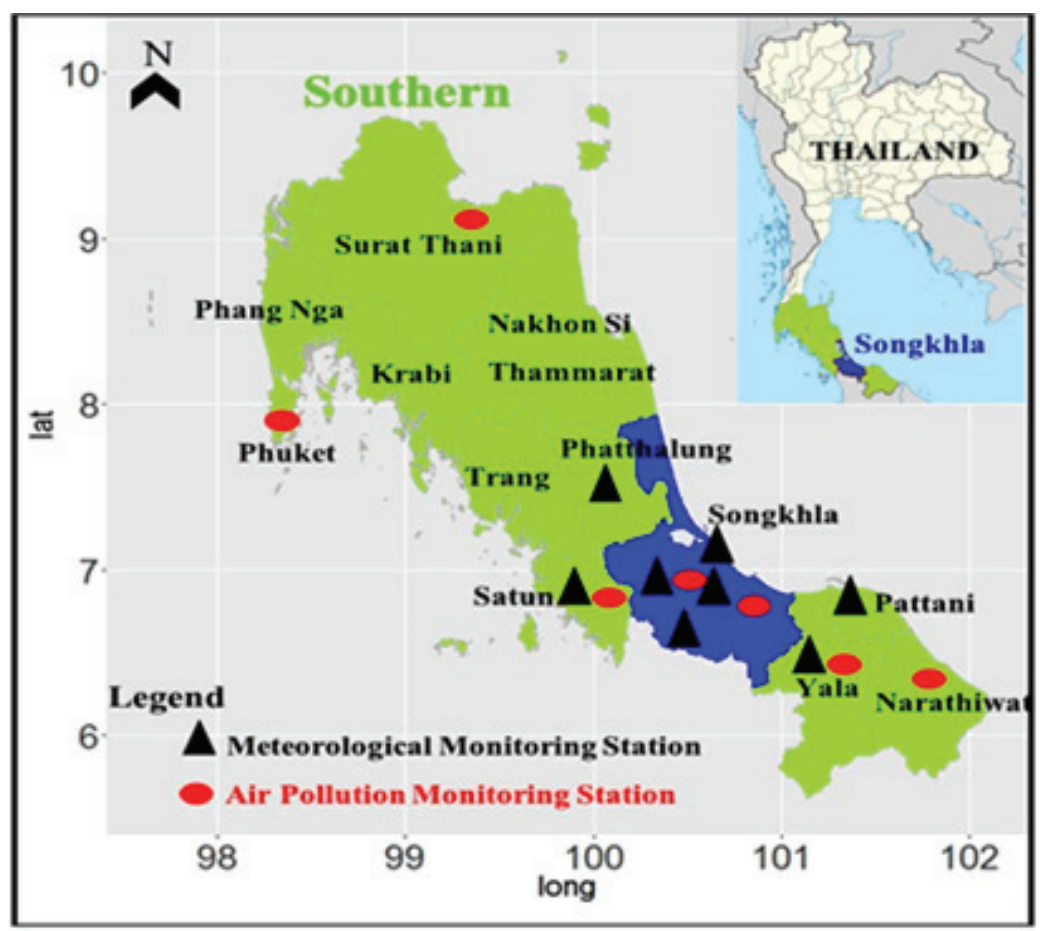

A

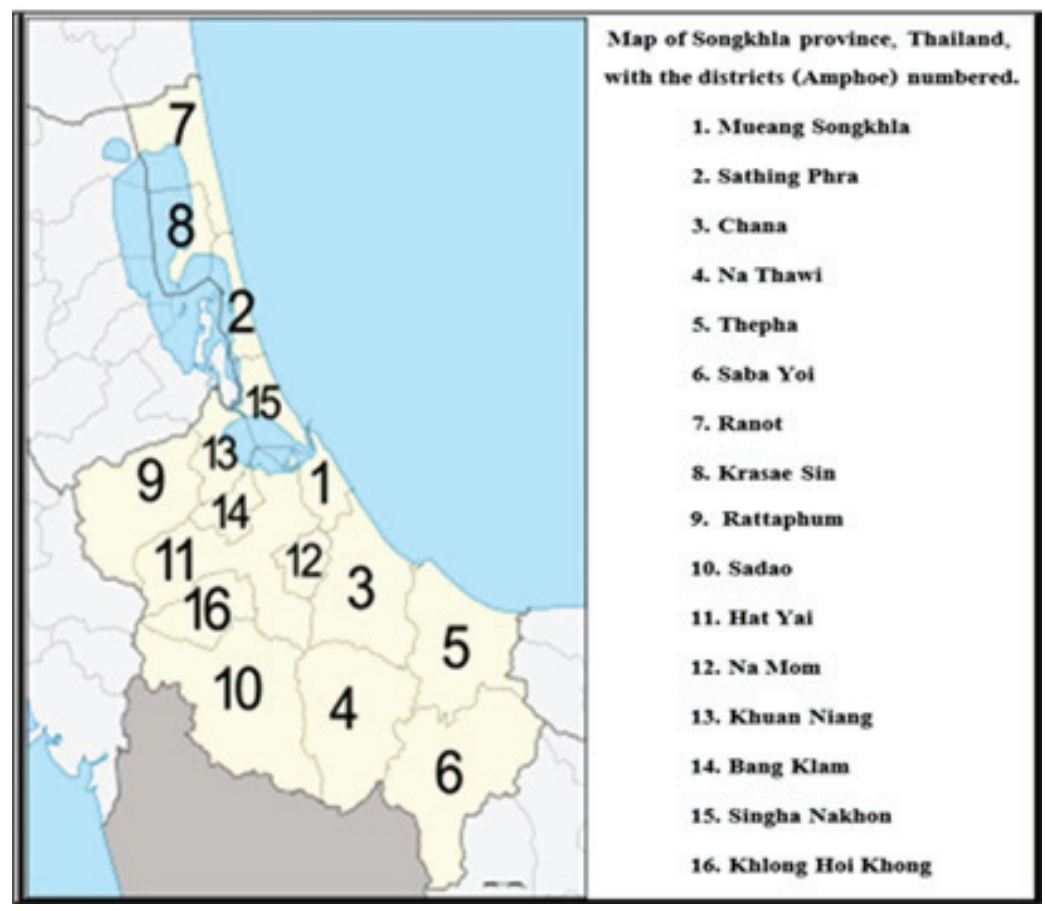

B 
Additional file 2 Statistical methods. Poisson regression using a generalized additive model combined with distributed lag non-linear model to analyze the associations between air pollution and asthma outpatient visit. The model is expressed as follows:

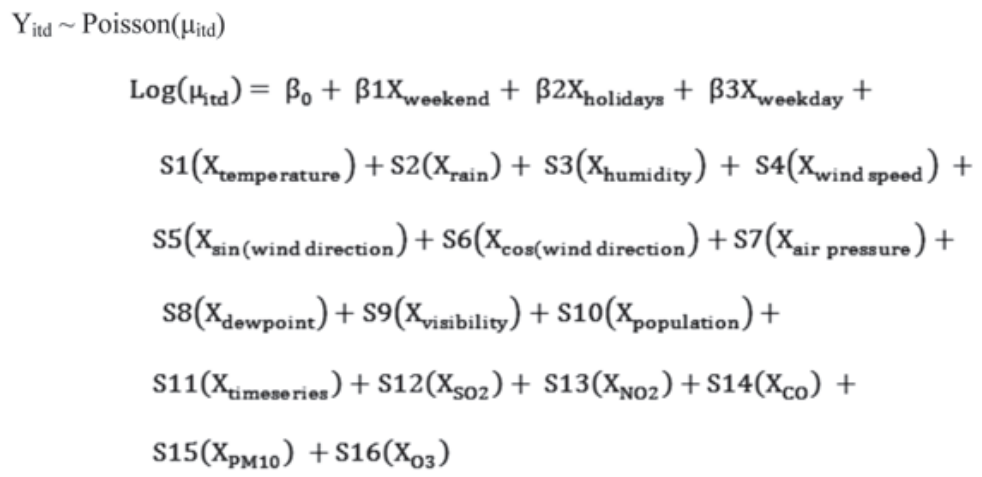

Where $\mathrm{i}=1,2,3, \ldots, 127$ (127 sub-districts), $\mathrm{t}=2013,2014,2015,2016,2017$ (year), $\mathrm{d}=1,2, \ldots, 1825$ (day).

\begin{tabular}{|c|c|}
\hline$Y_{\text {itd }}$ & : Daily asthma outpatient visits in each sub-district. \\
\hline$\mu_{\text {itd }}$ & : Daily average asthma outpatient visits in each sub-district. \\
\hline & : weekend/Non-Weekend \\
\hline & : Thai holidays and observatories. \\
\hline $\mathrm{X}_{\text {weekday }}$ & : Weekly cycle, from Monday to Sunday. \\
\hline $\mathrm{X}_{\text {population }}^{\text {weéaay }}$ & : Population in age groups in each sub-district. \\
\hline & : Daily average temperature in each sub-district. \\
\hline$X_{\text {rain }}$ & : Daily average rain in each sub-district. \\
\hline$X_{\text {humidity }}^{\text {rain }}$ & : Daily average relative humidity in each sub-district. \\
\hline & : Daily average wind speed in each sub-district. \\
\hline & : Daily average wind direction in each sub-district. \\
\hline$X_{\text {air pressure }}$ & : Daily average air pressure in each sub-district. \\
\hline & : Daily average dewpoint in each sub-district. \\
\hline & : Daily average visibility in each sub-district. \\
\hline$x_{\text {timeseries }} \times x \times$ & : Daily cycle, from first day to the last day in the study period $(1,2, \ldots, 1825)$ \\
\hline $\begin{array}{l}\mathrm{X}_{\mathrm{PM10}}, \mathrm{X}_{\mathrm{SO2}}, \mathrm{X}_{\mathrm{CO}}, \mathrm{X}_{\mathrm{NO2}}, \mathrm{X}_{\mathrm{CO}} \\
\mathrm{S} 1-\mathrm{S} 16\end{array}$ & $\begin{array}{l}\text { : Five estimated daily average concentration of pollutants in each sub-district. } \\
\text { : Smoothing function (Cubic smoothing Spline) }\end{array}$ \\
\hline
\end{tabular}


Additional file 3 Shows a smoothing functions for selecting a cutpoint on 3 age-related groups: children (0 - 19 years), adults (20-64 years), and elderly ( $\geq 65$ years)

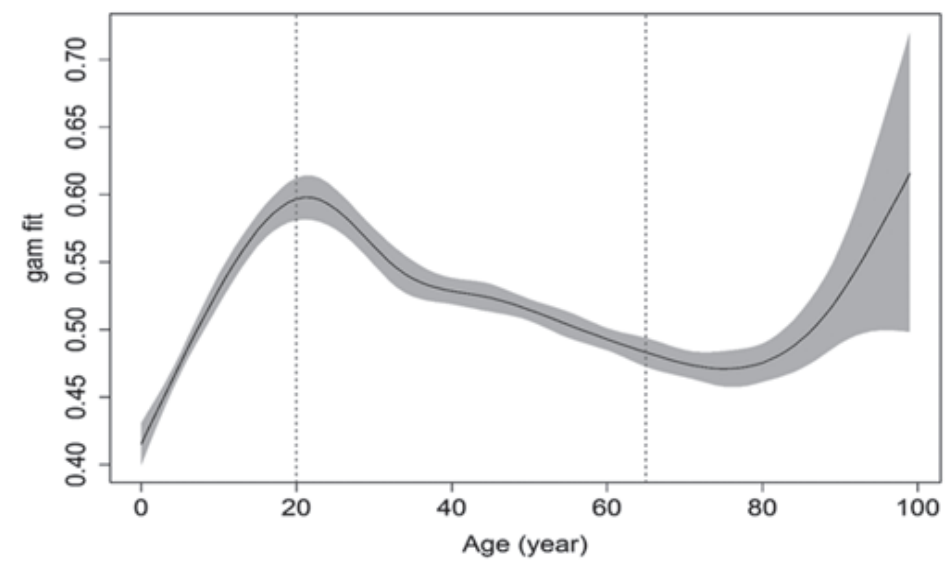

Additional file 4 Sub-districts level distribution of the asthma outpatient visits morbidity rate in the Songkhla province, 2013-

2017.
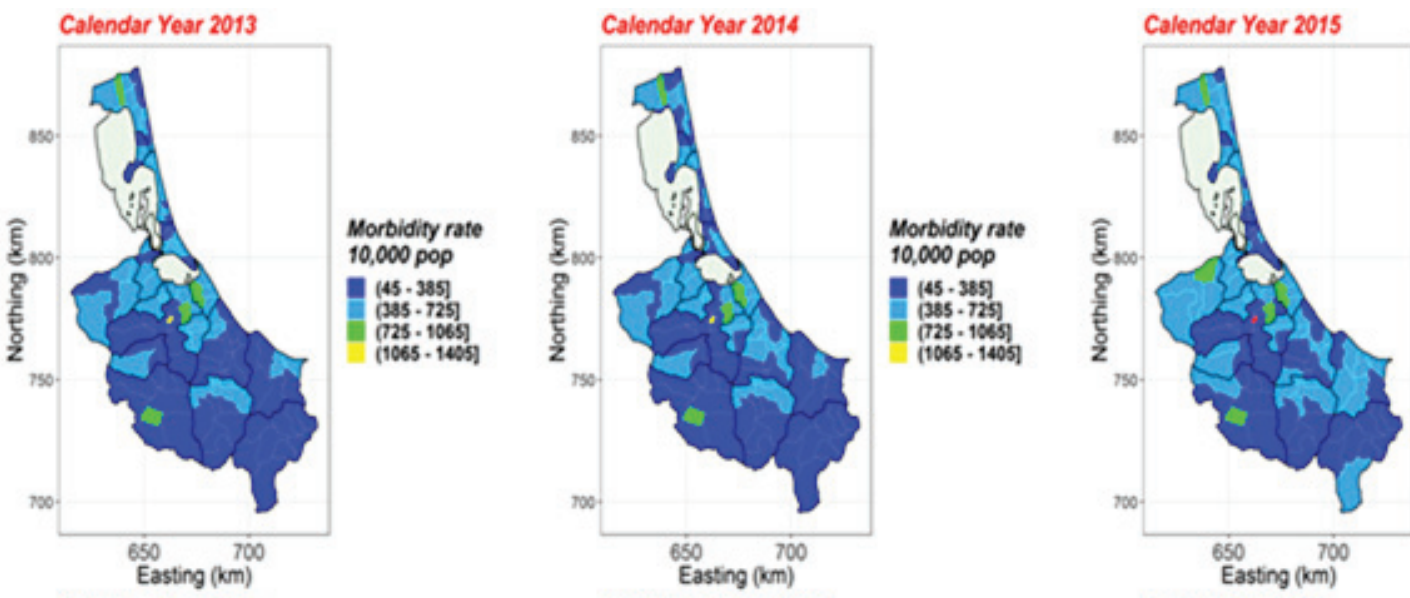

Morbidity rate

Morbidity rate 10,000 pop

[145-385)

$725 \cdot-1065)$
$(1065 \cdot 1655)$
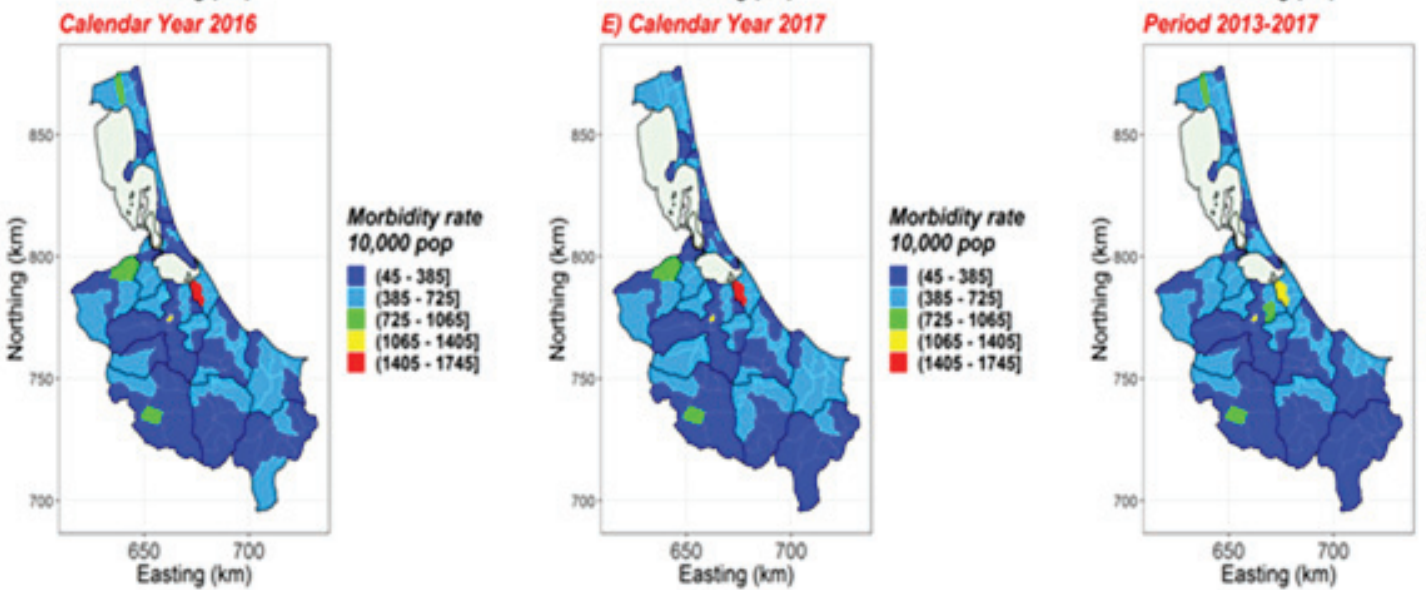

, 000 pop

- 145 - 1951

(1935.725

$(1405.1745)$

Morbidity rate 10,000 pop

(45 - 385)

(725. 1065$)$

(1065 - 1405) 